University of Wollongong

Research Online

Faculty of Science, Medicine and Health -

Papers: part A

Faculty of Science, Medicine and Health

$1-1-2014$

\title{
Testing the ability of topoclimatic grids of extreme temperatures to explain the distribution of the endangered brush-tailed rock-wallaby (Petrogale penicillata)
}

\author{
Michael B. Ashcroft \\ Australian Museum, ashcroft@uow.edu.au \\ Mike Cavanagh \\ NSW Office of Environment and Heritage \\ Mark D. Eldridge \\ Macquarie University \\ John R. Gollan \\ University of Technology Sydney
}

Follow this and additional works at: https://ro.uow.edu.au/smhpapers

Part of the Medicine and Health Sciences Commons, and the Social and Behavioral Sciences

Commons

\section{Recommended Citation}

Ashcroft, Michael B.; Cavanagh, Mike; Eldridge, Mark D.; and Gollan, John R., "Testing the ability of topoclimatic grids of extreme temperatures to explain the distribution of the endangered brush-tailed rock-wallaby (Petrogale penicillata)" (2014). Faculty of Science, Medicine and Health - Papers: part A. 2788.

https://ro.uow.edu.au/smhpapers/2788

Research Online is the open access institutional repository for the University of Wollongong. For further information contact the UOW Library: research-pubs@uow.edu.au 


\title{
Testing the ability of topoclimatic grids of extreme temperatures to explain the distribution of the endangered brush-tailed rock-wallaby (Petrogale penicillata)
}

\author{
Abstract \\ Aim Many species are susceptible to climatic extremes, yet few fine-scale studies consider the factors \\ that determine the distribution of extreme temperatures at landscape and regional scales. These factors \\ include cold air drainage, canopy cover and topographical exposure to winds and radiation. We used the \\ brush-tailed rock-wallaby (Petrogale penicillata) to test whether innovative topoclimatic grids of extreme \\ temperatures are an important predictor of regional-scale species distributions. Location Hunter Valley \\ region, New South Wales, Australia (31.2-33.4 $\left.{ }^{\circ} \mathrm{S}, 148.6-153.0^{\circ} \mathrm{E}\right)$. Methods We modelled the regional \\ distributions of rock-wallaby observations and colonies using topoclimatic, macroclimatic, topographical \\ and habitat factors. We employed a randomization procedure to reduce spatial clustering of records and \\ divide the data into 10 different training and testing datasets. Models were assessed using the Akaike \\ information criterion (AIC) on the training datasets, the area under the receiver operating characteristic \\ curve (AUC) on the test datasets, and the consistency of the response curves. We compared multiple \\ univariate and multivariate models, rather than producing one 'true' model, to examine the evidence that \\ different environmental factors consistently influenced the distribution of rock-wallabies. Results The \\ environmental factors that were consistently strongest at explaining the distribution of rock-wallabies \\ were the topoclimatic estimate of extreme cold, the macroclimatic estimate of annual precipitation, and \\ the amount of cleared land within $1600 \mathrm{~m}$. Rock-wallaby colonies were in areas where minimum \\ temperatures were high, rainfall was low, and there was a low proportion of cleared land. Topographical \\ surrogates performed well in univariate models but poorly in multivariate models. Main conclusions We \\ have shown that topoclimatic maps of extreme conditions have the potential to model the regional \\ distributions of at least some species better than indirect surrogates based on topography or \\ macroclimate. Topoclimatic grids are an important tool for regional conservation planning, but \\ practitioners need to place more emphasis on the derivation and accuracy of the climate grids, not just \\ the spatial resolution.

\section{Disciplines} \\ Medicine and Health Sciences | Social and Behavioral Sciences

\section{Publication Details} \\ Ashcroft, M. B., Cavanagh, M., Eldridge, M. D. \& Gollan, J. R. (2014). Testing the ability of topoclimatic \\ grids of extreme temperatures to explain the distribution of the endangered brush-tailed rock-wallaby \\ (Petrogale penicillata). Journal of Biogeography, 41 (7), 1402-1413.
}


Original Article

LRH M. B. Ashcroft et al.

RRH Topoclimatic extremes and the distribution of rock-wallabies

Testing the ability of topoclimatic grids of extreme temperatures to explain the distribution of the endangered brush-tailed rock-wallaby (Petrogale penicillata)

Michael B. Ashcroft ${ }^{1,2}$, Mike Cavanagh ${ }^{3}$, Mark D. B. Eldridge ${ }^{1}$ and John R. Gollan ${ }^{1,4}$

${ }^{1}$ Australian Museum, Sydney, NSW, 2010, Australia, ${ }^{2}$ Australian Wetlands, Rivers and Landscapes Centre, School of Biological, Earth and Environmental Sciences, The University of New South Wales, NSW, 2052, Australia, ${ }^{3}$ NSW Office of Environment and Heritage, Hurstville, NSW, 2220, Australia, ${ }^{4}$ University of Technology, Sydney, School of the Environment, Broadway, NSW, 2007, Australia

*Correspondence: Mick Ashcroft, Australian Museum, 6 College St, Sydney, NSW, 2010, Australia.

Email: Mick.Ashcroft@austmus.gov.au 


\section{ABSTRACT}

Aim Many species are susceptible to climatic extremes, yet few fine-scale studies consider the factors that determine the distribution of extreme temperatures at landscape and regional scales. These factors include cold air drainage, canopy cover and topographical exposure to winds and radiation. We used the brush-tailed rock-wallaby (Petrogale penicillata) to test whether innovative topoclimatic grids of extreme temperatures are an important predictor of regional-scale species distributions.

Location Hunter Valley region, New South Wales, Australia (31.2-33.4 S, 148.6-153.0 E)

Methods We modelled the regional distributions of rock-wallaby observations and colonies using topoclimatic, macroclimatic, topographical and habitat factors. We employed a randomization procedure to reduce spatial clustering of records and divide the data into 10 different training and testing datasets. Models were assessed using the Akaike information criterion (AIC) on the training datasets, the area under the receiver operating characteristic curve (AUC) on the test datasets, and the consistency of the response curves. We compared multiple univariate and multivariate models, rather than producing one 'true' model, to examine the evidence that different environmental factors consistently influenced the distribution of rock-wallabies.

Results The environmental factors that were consistently strongest at explaining the distribution of rock-wallabies were the topoclimatic estimate of extreme cold, the macroclimatic estimate of annual precipitation, and the amount of cleared land within 1600 m. Rock-wallaby colonies were in areas where minimum temperatures were high, rainfall 
was low, and there was a low proportion of cleared land. Topographical surrogates performed well in univariate models but poorly in multivariate models.

Main conclusions We have shown that topoclimatic maps of extreme conditions have the potential to model the regional distributions of at least some species better than indirect surrogates based on topography or macroclimate. Topoclimatic grids are an important tool for regional conservation planning, but practitioners need to place more emphasis on the derivation and accuracy of the climate grids, not just the spatial resolution.

\section{Keywords}

Behavioural adaptation, climate refuges, cold air drainage, ecological niche model, minimum temperatures, physiologically sensitive, predictor selection, regional scale, species distribution model, topoclimate.

\section{INTRODUCTION}

Biodiversity is threatened by climate change, introduced species and intensifying human land use, but our ability to predict how species will respond to these threats is constrained by our limited mechanistic understanding of the factors affecting their distributions (the Hutchinsonian shortfall; Mokany \& Ferrier, 2011). Despite repeated calls for a strong ecological basis underpinning species distribution models (SDMs; Austin, 2002, 2007; Austin \& Van Niel, 2011a), distributions are still often explained using models with only coarse-scale climatic predictors (bioclimatic envelope models; Araújo \& Peterson, 2012). This is partially because some scientists view climate as the dominant factor affecting coarsescale distributions (Pearson \& Dawson, 2003; but see Hampe, 2004; Bertrand et al., 2012), 
but also because of the relative ease with which these coarse-scale models can be produced using freely available data on species distributions and macroclimatic variables (e.g. WorldClim; Hijmans et al., 2005).

There is now increasing recognition that these coarse-scale bioclimatic envelope models are of limited use for environmental management, as most planning decisions are made within individual regions (Ferrier et al., 2002; Lookingbill \& Urban, 2003; Cabeza et al., 2010). Greater emphasis needs to be placed on producing fine-scale models using a broader range of ecologically relevant variables (Austin \& Van Niel, 2011b); this could, for example, help identify microrefugia where species may be able to escape the effects of climate change that are predicted by coarse-scale models (Ashcroft, 2010; Dobrowski, 2011). Climate has sometimes been discounted as influencing species distributions at fine scales, as it is assumed factors such as habitat are more important (e.g. Pearson \& Dawson, 2003; Illán et al., 2010). However, it is premature to discount the predictive ability of climate at a landscape scale before it has been assessed using appropriately fine-scaled topoclimatic grids (Gillingham et al., 2012). It has now been a decade since Lookingbill \& Urban (2003, 2005) proposed that the next generation of gradient analysis should be based on landscape-scale empirical data of environmental variables rather than indirect macroclimatic or topographical surrogates, yet their vision has yet to be fully realized.

Coarse-scale climate grids are often interpolated from weather stations using only elevation and geographical location (e.g. Bioclim and WorldClim; Houlder et al., 2003; Hijmans et al., 2005), but a broader range of climate-forcing factors needs to be considered when producing fine-scale grids, including topographical exposure to winds and radiation, cold air drainage and canopy cover (Daly, 2006). Many studies have assessed the effects of fine-scale climate 
on species distributions using climate grids that are still based predominately on elevation (e.g. Guisan et al., 2007; Trivedi et al., 2008; Randin et al., 2009; Franklin et al., 2013; Storlie et al., 2013). This may occur if: (1) the interpolation or downscaling method focuses predominately on elevation; (2) observations do not cover a sufficient diversity of environments to determine the effects of other factors; or (3) the time period or weather conditions relevant to the data are dominated by well-mixed atmospheric conditions or mild conditions. Elevation may appear to be a good predictor of fine-scale climate under these conditions, but it is poor at explaining the hottest and coldest temperatures that typically occur on specific days under relatively stable atmospheric conditions (Lundquist \& Cayan, 2007; Dobrowski et al., 2009; Ashcroft \& Gollan, 2012). As these extreme temperatures can have dramatic effects on biodiversity (Bateman et al., 2012; Thompson et al., 2013), this is an important shortcoming in our understanding of how fine-scale climate affects species distributions.

The goal of this study was to determine how well fine-scale estimates of extreme temperatures, which are poorly correlated with elevation, could explain species distributions. We addressed this goal using a case study of the endangered brush-tailed rock-wallaby, Petrogale penicillata (Gray, 1825), in the Hunter Valley region of New South Wales (NSW), Australia. This species is typically found in elevated rocky areas and, while rock shelters are recognized as being important at a local scale, we hypothesized that topoclimate would also be an important determinant of its distributions at a regional scale. However, to test this theory we needed to separate the effects of topoclimate from other topographical, vegetative and macroclimatic variables. That is, we needed to determine whether rock-wallabies were typically observed in elevated rocky areas because of the underlying topography, the unique 
topoclimates in these locations, or the fact that these areas were generally more vegetated than the disturbed lowland areas (predation risk was considered to be higher in more open areas).

In particular, we predicted that topoclimatic estimates of extreme minimum temperatures would be good at explaining the regional distribution of rock-wallabies in this study area, and that they would be found in places that were less exposed to extreme cold, because of the following. (1) The habitats where they were perceived to be found were areas where minimum temperatures are likely to remain high (e.g. hilltops and forested slopes; Ashcroft \& Gollan, 2012). (2) Rock-wallabies have been observed to be less active at night in colder regions and, despite being a timid species, individuals risk exposure to predators by basking in the sun to warm up in cold weather (Eldridge \& Close, 2008). (3) Rock-wallabies have ancestral lineages of a tropical origin (Potter et al., 2012), and brush-tailed rock-wallabies occupy regions that are cooler than the climate experienced by their ancestors. Although rock-wallabies have occurred in colder climates to the south and west of the current study area, these are the areas from which they have contracted most over the last 200 years (Eldridge \& Close, 2008) and it is possible that a greater need for basking in colder areas also places them at higher predation risk. (4) At least two other congeners (Petrogale lateralis and Petrogale rothschildi) rely on behaviour to avoid thermal heat stress by sheltering in caves (Bradshaw et al., 2001; King \& Bradshaw, 2008). It is therefore possible that brush-tailed rock-wallabies also use their basking behaviour to avoid cold stress if physiological sensitivity is maintained under niche conservatism (Crisp et al., 2009). (5) The changing local habitat preferences of this species with geographical location (Murray et al., 2009, 2011) may indicate that the species is seeking to maintain a suitable microclimate (see 
examples of this in Suggitt et al., 2011). There were thus good reasons to believe that rockwallabies may be physiologically sensitive to extreme cold, and that topoclimatic estimates of extreme cold would be a good predictor of their regional distributions in this study area.

\section{MATERIALS AND METHODS}

\section{Study area}

Our study was conducted in the greater Hunter Valley region of NSW, Australia (31.233.4 S, 148.6-153.0 E; c. 96,000 km²; Fig. 1). The Hunter Valley runs north-west-southeast through the middle of our study area, and has been largely cleared for agriculture and open-cut mining. Small patches of eucalypt woodlands and forests remain in the valley, and occasionally rain forests in sheltered locations in more rugged areas. The mountains to the north and south of the valley contain a much wider diversity of forests, perched swamps and woodlands, and rain forest patches are more common. Rocky outcrops are also more common in these mountains, especially in the south, where there are mesas with sandstone cliffs. The climate is temperate, with mean annual temperatures ranging from c. 9 to $19{ }^{\circ} \mathrm{C}$, a mean annual precipitation of 500-2000 mm, and snow restricted to rare events on the highest mountains (c. $1600 \mathrm{~m})$.

\section{Biotic data}

As their name suggests, rock-wallabies inhabit rocky outcrops, where they find shelter from predators and harsh environmental conditions (DECC, 2008a). However, perceived habitat preferences vary in space (Murray et al., 2009, 2011) and they can also be found in areas without rocky outcrops or use vegetation for shelter (DECC, 2008a; Eldridge, 2008). Their 
distribution has contracted in the 200 years since European settlement in Australia, with fox (Vulpes vulpes) predation and hunting reducing their numbers dramatically (DECC, 2008a). Their general preference for elevated, rocky habitats may not have changed, but many populations at sites with simpler shelters have been lost and persistence is more likely where more complex shelters allow them to be less vulnerable to introduced predators (DECC, 2008a). The overall distribution of brush-tailed rock-wallabies extends from Victoria, in south-east Australia, to southern Queensland. There are three recognized evolutionarily significant units (ESUs) within the species (Browning et al., 2001), and the current study area includes the northern portion of the central ESU and the southern portion of the northern ESU (DECC, 2008a).

Brush-tailed rock-wallabies live in colonies of c. 2-70 individuals (DECC, 2008a), and generally have core home ranges of $2-3$ ha and overall home ranges of $c$. 25 ha (Laws \& Goldizen, 2003; Murray et al., 2009; Molyneux et al., 2011). We produced one model using all available records, and another one using just the probable extant colonies. Models produced using all records of a species are more likely to be influenced by dispersing and foraging individuals and potentially sink populations, and thus include observations in marginal habitat (Soberón, 2007). Therefore modelling was also done using just the probable colonies to provide better information on the actual environmental conditions in the core habitats that support population persistence.

All records of brush-tailed rock-wallabies in the study area were obtained from the Atlas of living Australia (http://www.ala.org.au/) on 16 March 2012. These were combined with the records in a personal database maintained by one of the authors (M.C.), and represented a combination of targeted surveys and ad hoc observations. Records dated back to 1788, but 
c. $80 \%$ of the records were collected after 1990 . Records were quality controlled based on the certainty of taxonomy, spatial location, survey reports, reliability information supplied with the records, site visits to confirm occupation or suitable shelters, or expert or local knowledge. While there was some subjectivity in the quality control, the procedure was precautionary in that records were only labelled 'extant colonies' if there was a high level of certainty that rock-wallabies had occupied the site in more than a temporary manner. While some of these sites may have ceased to be occupied since the observations were made, they were still considered to represent higher quality sites that provided suitable conditions for the persistence of colonies.

The records displayed a large amount of spatial clustering, which can be problematic for models as nearby observations are not independent and it can place too much weight on the limited set of environmental conditions in heavily surveyed areas. To reduce the effects of this issue, we divided the study area into a $0.05^{\circ} \times 0.05^{\circ}$ grid $(c .5 \mathrm{~km})$ and randomly selected one presence from within each grid cell that contained at least one record (while maintaining the spatial accuracy of records and the resolution of the predictors). The data were then randomly divided into training and test datasets, and a set of randomly generated pseudoabsences from the whole study area was added. This process was repeated 10 times so that each training dataset for colonies had 31 presences and 200 pseudo-absences, and each test dataset had 14 presences and 100 pseudo-absences. Similarly, each training dataset for all observations had 110 presences and 200 pseudo-absences, and each test dataset had 48 presences and 100 pseudo-absences. The entire dataset consisted of 134 observations of colonies and 475 observations in total. 


\section{Environmental data}

Fifteen environmental predictors were used in this study, including four macroclimatic variables, four topoclimatic variables, four topographical variables, and three habitat variables, each available as GIS raster layers (Table 1). The four macroclimatic variables were created using the ANUCLIM 6.1 software package (Houlder et al., 2003) and a c. 50-m resolution digital elevation model (DEM) for the study area. Although these variables had fine spatial resolution, they were interpolated based only on elevation and location rather than the broader range of factors affecting fine-scale climate (Daly, 2006), and were thus considered to represent the macroclimate. To capture a range of macroclimatic predictors, we selected mean annual temperature (AnnTmp), mean annual precipitation (AnnPr), maximum temperature of the warmest period (MaxTmp) and minimum temperature of the coldest period (MinTmp). Although a larger number of bioclimatic predictors was available, there was no a priori reason to believe any of the others would be more biologically relevant; many were correlated with the selected predictors, and including too many bioclimatic predictors increases the risk of over-fitting (Beaumont et al., 2005).

The $c .25-\mathrm{m}$ resolution rasters of the topoclimatic predictors were produced using data from a network of 127 DS1923 hygrochron iButtons (Maxim, San Jose, CA, U.S.A.), which recorded hourly temperature and humidity for 340 days between June 2009 and May 2010. These observations were made across a diversity of habitats, and the climate grids were interpolated using a broader range of climate-forcing factors, including cold air drainage, topographical exposure to winds and radiation, and canopy cover (Ashcroft \& Gollan, 2012). While one year of data was insufficient to capture long-term topoclimatic averages accurately, the patterns identified provided a good indication of the relative differences 
between different habitats, and consistent patterns have since been confirmed with subsequent data collection (M.B.A. and J.R.G. unpublished data). We selected two topoclimatic variables that represented extreme conditions and were each poorly correlated with elevation (Table 1). The 5th percentile of daily minimum temperatures (MinT5) represented the coldest conditions experienced at each site, even if they were not recorded simultaneously or consecutively, and this exposure to cold extremes was largely determined by cold air drainage (Ashcroft \& Gollan, 2012). Cold air drainage is common under clear skies, low wind and anticyclonic conditions, as a lack of atmospheric mixing allows the heavier cold air to drain downhill and form local temperature inversions. In contrast to macroclimatic variables, topoclimatic predictors captured the fact that local topographical maxima experienced extreme minimum temperatures that were $c .9^{\circ} \mathrm{C}$ warmer than the surrounding valleys.

The second topoclimatic variable was the 95th percentile of maximum temperatures (MaxT95), which represented the hottest conditions at each site; this exposure to warm extremes was largely influenced by canopy cover and topographical exposure. For example, sheltered rain forest gorges are cooler in terms of maximum temperatures than more exposed areas (Ashcroft et al., 2008). Two other topoclimatic variables were also considered. The 95th percentile of minimum temperatures (MinT95) was included as an indicator of mild conditions but, as discussed earlier, these mild conditions are influenced strongly by elevation ( $r=-0.93$; Table 1 ) and so the differences from macroclimatic predictors were less apparent. Finally, we included the 5th percentile of daily minimum humidities as an indicator of the driest conditions (MinH5), which were influenced by a combination of MaxT95 ( $r=-$ 0.92) and AnnPr ( $r=0.87$; Table 1$)$. 
The four topographical predictors were elevation (Elev), taken from a DEM with a resolution of $c .25 \mathrm{~m}$, the derived slope (Slp) and cosine of aspect (Asp; an indicator of whether slopes face north or south), and the relative elevation within a 500-m radius (RelElev). The relative elevation was calculated using a moving window, and was the difference between the elevation of a cell and the minimum elevation of all cells within a 500-m radius. The relative elevation has been shown to be a good predictor of cold air drainage in semi-arid, subalpine and temperate study areas (Bennie et al., 2010; Ashcroft \& Gollan, 2012, 2013) and was the dominant variable used to create the MinT5 topoclimatic variable (Ashcroft \& Gollan, 2012). The four topographical variables were included because it is time consuming to produce topoclimatic grids and it is more cost efficient to use topographical surrogates if model performance is similar. In addition, topography may also have a direct impact on rockwallaby distributions.

The three habitat variables were based on the vegetation at each site. The first (VegCom) was the vegetation community based on the 200-m resolution state-wide vegetation data (Keith 2002). This was included as a general indication of vegetation structure but the resolution was too coarse to pick up some smaller patches of rain forest. The layer was reclassified into shrubby forests (wet or dry sclerophyll forests with shrubby understoreys), rain forests (rain forests or wet sclerophyll with grassy understoreys) or other (shrublands, woodlands, wetlands and grasslands) to reduce the number of categories. The foliage projected cover, or percentage of the ground occupied by the vertical projection of vegetation (FolCov), was obtained from a $c$. 30-m resolution remotely sensed grid produced by the NSW Office of Environment and Heritage (DECC, 2008b). This layer was used directly as a predictor, and to create a contextual raster based on the amount of cleared land within $1600 \mathrm{~m}$ of each cell 
(ClrCont). Cleared land was defined as areas where FolCov was less than 20\%, and then we calculated the amount of cleared land within $1600 \mathrm{~m}$ using the Focal Statistics tool in ARCMAP 10.1 (ESRI, Redlands, CA, USA).

\section{Analysis}

Our goal was to assess the importance of different environmental factors, and in particular to determine whether rock-wallabies favoured areas where minimum temperatures remained high. This is different to selecting and evaluating one 'true model', as many models can perform similarly when predictors are correlated and the best model does not necessarily contain the most ecologically relevant predictors (Mac Nally, 2002). Therefore, methods such as step-wise regression are not well suited to evaluating the performance of individual predictors (Mac Nally, 2002). An alternative is to look for predictors that consistently perform well across multiple species, predictor combinations, or randomized datasets (e.g. Mac Nally, 2002; Ashcroft et al., 2011). In this study, our 10 randomized datasets (see Biotic Data) only contained around a quarter of the original data. This introduced variability into the results and reduced the chances of a predictor appearing to be important because of a spurious correlation, as it would have to perform consistently well across a number of different datasets in both univariate and multivariate models.

We fitted generalized additive models (GAMs) using the gam package in R (R Development Core Team, 2010), with a binomial family and logit link function. The response variable was the presence or absence of rock-wallabies, in terms of either probable colonies or all records, as detailed above. Predictors were either categorical (VegCom) or continuous variables included as splines with two degrees of freedom. We tested all 15 univariate models using the 
predictors detailed above, and examined the strength of evidence that each predictor was important by examining the Akaike information criterion (AIC; Burnham \& Anderson, 2002) of the training data to assess parsimony, the area under the receiver operating characteristic curve (AUC; Swets, 1988) of the test data to test predictive ability, and the species response curves generated by the GAMs to assess consistency qualitatively. Better models would have lower AIC, higher AUC and consistent response curves across the 10 replicate datasets. We used a paired $t$-test to determine whether any predictor was consistently better than the others in terms of AIC or AUC across the 10 replicate datasets. We then produced multivariate models; however, to reduce the number of models we only included combinations containing at least one of the best predictors from the univariate models. Spatial maps were produced using the average response of the 10 replicate models.

\section{RESULTS}

\section{Factors affecting the distribution of extant colonies}

There was no one environmental factor that was consistently or significantly better than the others in the univariate models for rock-wallaby colonies (Fig. 2a). Topoclimatic minimum temperatures (MinT5), relative elevation (RelElev), slope (Slp) and two habitat predictors (VegCom and ClrCont) all had an AIC < 151 and an AUC > 0.777, which was significantly better than the other 10 predictors (AIC $>164$, AUC $<0.747$; $P<0.05$ ), but none of these five were consistently best. We then tested all combinations of two-predictor models that included one of the above five predictors. We found that the combination of MinT5 and mean annual precipitation (AnnPr) was significantly better than all other combinations (Fig. 2b; AUC $=0.891$, AIC $=124$; all other models AUC $<0.875$, AIC $>132, P<0.05$ ). 
The best three-predictor model was the combination of MinT5, AnnPr and the amount of cleared land within 1600 m (ClrCont), with an AIC of 116 and AUC of 0.908. Rockwallabies were observed more frequently where rainfall was low, minimum temperatures were high and there was little cleared land in the surrounding area. This model was significantly better than other models in terms of AIC (other models AIC $>119, P<0.05$ ), but the differences in AUC were smaller and not significant in all cases (Fig. 2c). We did not examine models containing four or more predictors as many models performed similarly and it was not possible to identify confidently factors that affected the distribution of rockwallabies, even though it might have been possible to identify a model that was marginally better in statistical terms.

As predicted, rock-wallaby colonies were found in areas where minimum temperatures remained high, in both the univariate (Fig. 3a) and multivariate models (Fig. 3b). More uncertainty was added to the response curves as extra predictors were added into the models, but colonies were generally only found on low-elevation hills where extreme minimum temperatures were $c .5{ }^{\circ} \mathrm{C}$ or higher. The relative elevation predictor performed marginally better than MinT5 in terms of AUC in univariate models, but it was worse in terms of AIC, there was more uncertainty in the response curves, and it did not perform as well in multivariate models. Another potential topographical surrogate, slope, also performed well in univariate models but relatively poorly in multivariate models.

Macroclimatic predictors, such as MinTmp, and other predictors that were correlated with elevation, such as MinT95, performed poorly in univariate models, probably because they did not capture the climatic process (cold air drainage) that had the dominant effect on topographical minimum temperatures. However, AnnPr was consistently important in 
multivariate models (Fig. 2b,c), with colonies absent in areas with precipitation above c. 1500 mm (Fig. 3c,d). AnnPr improved models over those based only on MinT5 because it could explain why colonies were absent from the coastal and high-elevation areas where MinT5 and other topographical surrogates appeared to be suitable (Fig. 4).

Habitat factors were important in univariate models (Figs 2a \& 3e,f), with rock-wallaby colonies found in areas where there were shrubby forests or less than c. $50 \%$ cleared land in the surrounding $1600 \mathrm{~m}$. However, there was a large amount of uncertainty in the response in multivariate models (Fig. 3e,f), possibly because suitable vegetation was often found in topographically complex areas where MinT5 was high (the correlation between MinT5 and ClrCont was -0.72). While habitat appeared to be important for rock-wallaby colonies in both univariate and multivariate models, there was more uncertainty than with $A n n P r$ and MinT5.

\section{Factors affecting the distribution of all rock-wallaby records}

The best three-predictor model for all brush-tailed rock-wallaby records in terms of AIC was, as per colonies, the combination of MinT5, AnnPr and ClrCont $(\mathrm{AIC}=292$, AUC $=0.8315)$. However, the combination of MinTmp, AnnPr and ClrCont was marginally better in terms of AUC $($ AIC $=302$, AUC $=0.8324)$, and a number of other models also had AUC $>0.82$, indicating higher uncertainty. These models were also weaker than the models for colonies $(\mathrm{AUC}=0.908)$, so the models based on all records were weaker and more uncertain but still leant support to the same predictors as those that were important for colonies. The lower performance of models using all records was partially because of isolated occurrences of 
dispersing and foraging individuals in locations where MinT5 was too low for colonies (Fig. 4).

\section{DISCUSSION}

Our results show that topoclimatic estimates of extreme temperatures are an important component of species distribution models at a regional scale. While other studies have used fine-scale climate grids (e.g. Guisan et al., 2007; Trivedi et al., 2008; Randin et al., 2009; Franklin et al., 2013; Storlie et al., 2013), these often only reflect macroclimatic trends and are dominated by the effects of elevation. However, temperatures on the hottest days and coldest mornings are driven by a larger array of climate-forcing factors, including cold air drainage, topographical exposure to winds and radiation, and canopy cover (Daly, 2006; Ashcroft \& Gollan, 2012). It is crucial to consider these factors when producing climate grids to explain the distribution of species that are physiologically susceptible to extreme conditions.

Our results make intuitive sense for brush-tailed rock-wallabies, at least in this study area, as there are a number of lines of evidence to suggest that they are sensitive to cold temperatures (see Introduction). For example, they use behaviour to avoid cold stress (e.g. seeking shelter and basking in the sun) and are less active at nights and in wet weather in colder regions (Eldridge \& Close, 2008). However, temperatures are not always cold and the species can disperse to, or graze in, other areas in seasons or at times of days when temperatures are higher. Indeed, the models produced using all brush-tailed rock-wallaby records were weaker and extreme temperatures had somewhat less effect. This highlights the dangers of modelling species distributions using all records, as they are more likely to include dispersing and 
foraging individuals, extinct colonies in marginal habitat and possibly sink populations (Soberón, 2007). These records may be important for understanding the metapopulation dynamics and foraging of the species, but many of them will be in marginal habitat and including them in species distribution models will dilute the importance of the environmental conditions in the colony sites that are crucial for population persistence.

The applicability of the model to other regions occupied by the species still needs to be tested. If brush-tailed rock-wallabies are sensitive to extreme cold, then we would predict that southern populations are more marginal, and would have greater dependence on basking and topography to maintain appropriate conditions. The fact that southern populations are experiencing the largest decline is consistent with this prediction. We would also expect northern populations to be less exposed to extreme cold, but temperatures do drop below $5{ }^{\circ} \mathrm{C}$ in the northern parts of the range, so the species may still have some dependence on topography to avoid extreme cold.

The other factors that we identified as affecting the distribution of rock-wallabies were also credible. We found that rock-wallabies were not recorded in areas with high rainfall, and this is consistent with the study of Bradshaw et al. (2001), who found that the health of Rothschild's rock-wallabies (P. rothschildi) was lower after heavy rainfall. While this study was on a different species in a more arid environment, they are congeneric and so it is plausible that brush-tailed rock-wallabies have a similar physiological sensitivity given the principle of niche conservatism. However, the avoidance of high rainfall areas by brushtailed rock-wallabies may also be an indirect indicator of another mechanism, such as coastal influences (Fig. 4) or less opportunity for basking in the sun under cloudy skies. The preference for shrubby eucalypt forests is seen as advantageous for avoiding predators 
(Wong, 1993, 1997), although rock-wallabies feed on both grasses and shrubs. However, the vegetation habitat predictors were somewhat correlated with MinT5 $\left(r^{2}=0.5\right)$ and there was more uncertainty on the effects of vegetation. Neither topography nor vegetation explained rock-wallaby distributions as well as avoidance of extreme cold, although it is important to note that fox predation may have changed the distribution and habitat preferences of rockwallabies since the arrival of European settlers (e.g. Short, 1982; DECC, 2008a). The lack of data on pre-European rock-wallaby distributions means there is some uncertainty regarding their original habitat preferences, and fox predation may have introduced a bias if it is correlated with the predictors considered in our study. We therefore acknowledge the need to understand this important predator-prey relationship further.

It is also important to acknowledge that we did not use a lithology predictor in our study, despite the known relationship between our target species and rocky habitats. Brush-tailed rock-wallabies use a variety of rock shelters, varying in quality, and in some cases they do not use rock shelters at all. These local habitat preferences are known to vary both within and between regions (Murray et al., 2009, 2011) and we did not have a regional-scale predictor that could adequately capture these complexities. However, rock habitats would help refine our regional-scale models if they were applied at a finer-scale.

One weakness of the approach employed here is that the models are only based on correlations between species occurrence and environmental factors. An alternative is to employ physiological models (e.g. Kearney et al., 2009, 2010), which directly relate the fitness of individuals to environmental conditions. However, to date physiological models have only been made for a limited number of species based on macroclimate, and ignore many of the factors contributing to topoclimatic models at a regional scale. An important area 
of future research is to combine topoclimatic and physiological modelling to increase ecological realism, although such models may only be possible for a small number of species because they will be time consuming and require large amounts of data.

As it is time consuming and expensive to develop topoclimatic grids using networks of iButton data loggers, it is also wise to consider whether similar results can be achieved using topographical surrogates. For example, Austin \& Van Niel (2011b) used topographical surrogate predictors in combination with macroclimatic variables in species distribution models for a Eucalyptus species. In our study we found a topographical surrogate for cold air drainage outperformed MinT5 in terms of AUC in univariate models (Fig. 3a,b); however, it underperformed in terms of AIC and also performed poorly in multivariate models. This can possibly be explained by the complex interactions between habitat and macroclimatic factors that occur when species change habitats throughout their ranges to maintain suitable microclimates (Suggitt et al., 2011). Indirect predictors may underperform when they require complex interactions with other terms in the models, and will be less applicable in a changing climate.

Another alternative is to use radiation models to estimate topoclimatic variability (Bennie et al., 2008). These models may be effective for some species and regions (e.g. Gillingham et al., 2012) but radiation is not always the dominant factor determining topoclimate. Cold air drainage is more important for extreme minimum temperatures, and the aspects of hottest and coldest topoclimates are not determined by radiation in cloudy or windy regions (Bennie et al., 2008; Ashcroft et al., 2008). We therefore suggest that topoclimatic grids based on empirical data have advantages over topographical surrogates or radiative models and should be used where possible. Furthermore, we reiterate Lookingbill \& Urban's (2005) view that 
this could lead to a new generation of gradient analysis by creating more direct predictors of species distributions (sensu Austin, 2002, 2007).

While topoclimatic estimates of extreme temperatures will help model the distributions of some physiologically sensitive species, they will not necessarily be useful for all species or communities. Some species have large home ranges, and fine-scale topoclimatic grids may be of little benefit in explaining their distributions unless a key portion of their life cycle (e.g. nesting) is restricted to a specific microenvironment. Other species may not be sensitive to extremes because they are not active or physiologically sensitive in the season or at the time of day when extremes occur. Rock-wallabies fit into these categories to some extent because they use shelters to escape climatic extremes (Bradshaw et al., 2001; King \& Bradshaw, 2008; DECC, 2008a), but our results suggest that they still favour warmer locations within the landscape to make this strategy more effective. Other species may use burrowing or nest hollows more effectively to reduce the impacts of climatic extremes. Ultimately, there are many stabilizing processes that may attenuate the effects of fine-scale topoclimatic variability on biodiversity (Lloret et al., 2012; Lenoir et al., 2013), and topoclimatic grids will be most useful for species that do not have an adequate strategy to avoid or cope with extreme conditions. If species do successfully avoid impacts of climatic extremes, then elevationsensitive interpolations may be adequate to model their distributions, as mild topoclimates correlate well with elevation.

There are, however, already other examples of species responding to fine-scale topoclimatic patterns of extreme conditions. For example, rain forest species in NSW often occur in sheltered topographical positions that are moister and cooler in terms of maximum temperatures, and their distribution is explained much better by topoclimate than elevation 
(Ashcroft et al., 2008). Similarly, topoclimatic models may outperform habitat factors at fine scales (Gillingham et al., 2012). The perceived importance of any factor at any scale is largely dependent on the accuracy with which it is estimated, and therefore we cannot properly assess the impacts of topoclimate unless we consider the effects of factors such as cold air drainage, canopy cover and topographical exposure. There is increasing recognition that the accuracy of climate data has often been overlooked (Soria-Auza et al., 2010) and that studies that ignore topoclimatic variation might reach incorrect conclusions (Dobrowski, 2011). However, to address these issues we need to place more emphasis on climate-forcing factors other than elevation, and assess quality by more than just the spatial resolution of the data (Daly, 2006).

\section{ACKNOWLEDGEMENTS}

This research was initiated by funding from the NSW Environmental Trust as part of the Great Eastern Ranges Conservation initiative (Grant GER-08-AM01), and continued as part of Australian Research Council Linkage Project LP100200080 in collaboration with the Australian Museum, University of Technology Sydney, Central West Catchment Management Authority, NSW Office of Water, and the Australian Wetlands, Rivers and Landscapes Centre at the University of New South Wales. We are grateful to more than 200 landowners who granted us permission to access their land, and to Dan Ramp for helpful discussions. 


\section{REFERENCES}

Araújo, M.B. \& Peterson, A.T. (2012) Uses and misuses of bioclimatic envelope modeling. Ecology, 93, 1527-1539.

Ashcroft, M.B. (2010) Identifying refugia from climate change. Journal of Biogeography, 37, $1407-1413$.

Ashcroft, M.B. \& Gollan, J.R. (2012) Fine-resolution (25 m) topoclimatic grids of nearsurface $(5 \mathrm{~cm})$ extreme temperatures and humidities across various habitats in a large $(200 \times$ $300 \mathrm{~km}$ ) and diverse region. International Journal of Climatology, 32, 2134-2148.

Ashcroft, M.B. \& Gollan, J.R. (2013) The sensitivity of topoclimatic models to fine-scale microclimatic variability and the relevance for ecological studies. Theoretical and Applied Climatology, 114, 281-289.

Ashcroft, M.B., Chisholm, L.A. \& French, K.O. (2008) The effect of exposure on landscape scale soil surface temperatures and species distribution models. Landscape Ecology, 23, 211225.

Ashcroft, M.B., French, K.O. \& Chisholm, L.A. (2011) An evaluation of environmental factors affecting species distributions. Ecological Modelling, 222, 524-531.

Austin, M.P. (2002) Spatial prediction of species distribution: an interface between ecological theory and statistical modelling. Ecological Modelling, 157, 101-118.

Austin, M. (2007) Species distribution models and ecological theory: a critical assessment and some possible new approaches. Ecological Modelling, 200, 1-19. 
Austin, M.P. \& Van Niel, K.P. (2011a) Improving species distribution models for climate change studies: variable selection and scale. Journal of Biogeography, 38, 1-8.

Austin, M.P. \& Van Niel, K.P. (2011b) Impact of landscape predictors on climate change modelling of species distributions: a case study with Eucalyptus fastigata in southern New South Wales, Australia. Journal of Biogeography, 38, 9-19.

Bateman, B.L., VanDerWal, J. \& Johnson, C.N. (2012) Nice weather for bettongs: using weather events, not climate means, in species distribution models. Ecography, 35, 306-314.

Beaumont, L.J., Hughes, L. \& Poulsen, M. (2005) Predicting species distributions: use of climatic parameters in BIOCLIM and its impact on predictions of species' current and future distributions. Ecological Modelling, 186, 251-270.

Bennie, J., Huntley, B., Wiltshire, A., Hill, M.O. \& Baxter, R. (2008) Slope, aspect and climate: spatially explicit and implicit models of topographic microclimate in chalk grassland. Ecological Modelling, 216, 47-59.

Bennie, J.J., Wiltshire, A.J., Joyce, A.N., Clark, D., Lloyd, A.R., Adamson, J., Parr, T., Baxter, R. \& Huntley, B. (2010) Characterising inter-annual variation in the spatial pattern of thermal microclimate in a UK upland using a combined empirical-physical model. Agricultural and Forest Meteorology, 150, 12-19.

Bertrand, R., Perez, V. \& Gégout, J.-C. (2012) Disregarding the edaphic dimension in species distribution models leads to the omission of crucial spatial information under climate change: the case of Quercus pubescens in France. Global Change Biology, 18, 2648-2660. 
Bradshaw, S.D., Morris, K.D. \& Bradshaw, F.J. (2001) Water and electrolyte homeostasis and kidney function of desert-dwelling marsupial wallabies in Western Australia. Journal of Comparative Physiology B, 171, 23-32.

Browning, T.L., Taggart, D.A., Rummery, C., Close, R.L. \& Eldridge, M.D.B. (2001) Multifaceted genetic analysis of the 'Critically Endangered' brush-tailed rock-wallaby Petrogale penicillata in Victoria, Australia: implications for management. Conservation Genetics, 2, 145-156.

Burnham, K.P. \& Anderson, D.R. (2002) Model selection and inference: a practical information-theoretic approach, 2nd edn. Springer-Verlag, New York.

Cabeza, M., Arponen, A., Jäättelä, L., Kujala, H., van Teeffelen, A. \& Hanksi, I. (2010) Conservation planning with insects at three different spatial scales. Ecography, 33, 54-63.

Crisp, M.D., Arroyo, M.T.K., Cook, L.G., Gandolfo, M.A., Jordan, G.J., McGlone, M.S., Weston, P.H., Westoby, M., Wilf, P. \& Linder, H.P. (2009) Phylogenetic biome conservatism on a global scale. Nature, 458, 754-756.

Daly, D. (2006) Guidelines for assessing the suitability of spatial climate data sets. International Journal of Climatology, 26, 707-721.

DECC (2008a) Recovery plan for the brush-tailed rock-wallaby (Petrogale penicillata). Department of Environment and Climate Change, Hurstville, NSW.

DECC (2008b) NSW Interim native vegetation extent (2008-Version 1). Report and data prepared by NSW Department of Environment and Climate Change for the national land and water resources audit. Department of Environment and Climate Change, Hurstville, NSW. 
Dobrowski, S.Z. (2011) A climatic basis for microrefugia: the influence of terrain on climate. Global Change Biology, 17, 1022-1035.

Dobrowski, S.Z., Abatzoglou, J.T., Greenberg, J.A. \& Schladow, S.G. (2009) How much influence does landscape-scale physiography have on air temperature in a mountain environment? Agricultural and Forest Meteorology, 149, 1751-1758.

Eldridge, M.D.B. (2008) Rock-wallabies Petrogale. The mammals of Australia, 3rd edn. (ed. by S.M. Van Dyck and R. Strahan), pp. 361-362. New Holland, Sydney.

Eldridge, M.D.B. \& Close, R.L. (2008) Brush-tailed rock wallaby Petrogale penicillata. The Mammals of Australia, 3rd edn (ed. by S.M. Van Dyck and R. Strahan), pp. 382-384. New Holland, Sydney.

Ferrier, S., Watson, G., Pearce, J. \& Drielsma, M. (2002) Extended statistical approaches to modelling spatial pattern in biodiversity in northeast New South Wales. I. Species-level modelling. Biodiversity and Conservation, 11, 2275-2307.

Franklin, J., Davis, F.W., Ikegami, M., Syphard, A.D., Flint, L.E., Flint, A.L. \& Hannah, L. (2013) Modeling plant species distributions under future climates: how fine scale do climate projections need to be? Global Change Biology, 19, 473-483.

Gillingham, P.K., Palmer, S.C.F., Huntley, B., Kunin, W.E., Chipperfield, J.D. \& Thomas, C.D. (2012) The relative importance of climate and habitat in determining the distributions of species at different spatial scales: a case study with ground beetles in Great Britain. Ecography, 35, 1-8. 
Guisan, A., Graham, C.H., Elith, J., Huettmann, F. \& NCEAS Species Distribution Modelling Group (2007) Sensitivity of predictive species distribution models to change in grain size. Diversity and Distributions, 13, 332-340.

Hampe, A. (2004) Bioclimate envelope models: what they detect and what they hide. Global Ecology and Biogeography, 13, 469-471.

Hijmans, R.J., Cameron, S.E., Parra, J.L., Jones, P.G. \& Jarvis, A. (2005) Very high resolution interpolated climate surfaces for global land areas. International Journal of Climatology, 25, 1965-1978.

Houlder, D., Hutchinson, M., Nix, H. \& McMahon, J. (2003) ANUCLIM 5.1 user's guide. Australian National University, Canberra.

Illán, J.G., Gutiérrez, D. \& Wilson, R.J. (2010) The contributions of topoclimate and land cover to species distributions and abundance: fine-resolution tests for a mountain butterfly fauna. Global Ecology and Biogeography, 19, 159-173.

Kearney, M., Shine, R. \& Porter, W.P. (2009) The potential for behavioral thermoregulation to buffer 'cold-blooded' animals against climate warming. Proceedings of the National Academy of Sciences USA, 106, 3835-3840.

Kearney, M.R., Wintle, B.A. \& Porter, W.P. (2010) Correlative and mechanistic models of species distribution provide congruent forecasts under climate change. Conservation Letters, 3, 203-213.

Keith D. (2002) A compilation map of native vegetation for New South Wales. NSW National Parks and Wildlife Service, Hurstville, NSW. 
King, J.M. \& Bradshaw, S.D. (2008) Comparative water metabolism of Barrow Island macropodid marsupials: hormonal versus behavioural-dependent mechanisms of body water conservation. General and Comparative Endocrinology, 155, 378-385.

Laws, R.J. \& Goldizen, A.W. (2003) Nocturnal home ranges and social interactions of the brush-tailed rock-wallaby Petrogale penicillata at Hurdle Creek, Queensland. Australian Mammalogy, 25, 169-176.

Lenoir, J., Graae, B.J., Aarrestad, P.A. et al. (2013) Local temperatures inferred from plant communities suggest strong spatial buffering of climate warming across Northern Europe. Global Change Biology, 19, 1470-1481.

Lloret, F., Escudero, A., Iriondo, J.M., Martínez-Vilalta, J. \& Valladares, F. (2012) Extreme climatic events and vegetation: the role of stabilizing processes. Global Change Biology, 18, 797-805.

Lookingbill, T.R. \& Urban, D L. (2003) Spatial estimation of air temperature differences for landscape-scale studies in montane environments. Agricultural and Forest Meteorology, 114, $141-151$.

Lookingbill, T.R. \& Urban, D L. (2005) Gradient analysis, the next generation: towards more plant-relevant explanatory variables. Canadian Journal of Forest Research, 35, 1744-1753.

Lundquist, J.D. \& Cayan, D.R. (2007) Surface temperature patterns in complex terrain: daily variations and long-term change in the central Sierra Nevada, California. Journal of Geophysical Research, 112, D11124. 
Mac Nally, R. (2002) Multiple regression and inference in ecology and conservation biology: further comments on identifying important predictor variables. Biodiversity and Conservation, 11, 1397-1401.

Mokany, K. \& Ferrier, S. (2011) Predicting impacts of climate change on biodiversity: a role for semi-mechanistic community-level modeling. Diversity and Distributions, 17, 374-380.

Molyneux, J., Taggart, D.A., Corrigan, A. \& Frey S. (2011) Home-range studies in a reintroduced brush-tailed rock-wallaby (Petrogale penicillata) population in the Grampians National Park, Victoria. Australian Mammalogy, 33, 128-134.

Murray, J.V., Goldizen, A.W., O’Leary, R.A., McAlpine, C.A., Possingham, H.P. \& Choy, S.L. (2009) How useful is expert opinion for predicting the distribution of a species within and beyond the region of expertise? A case study using brush-tailed rock-wallabies Petrogale penicillata. Journal of Applied Ecology, 46, 842-851.

Murray, J.V., Choy, S.L., McAlpine, C.A., Possingham, H.P. \& Goldizen, A.W. (2011) Evaluating model transferability for a threatened species to adjacent areas: implications for rock-wallaby conservation. Austral Ecology, 36, 76-89.

Pearson, R.G. \& Dawson, T.P. (2003) Predicting the impacts of climate change on the distribution of species: are bioclimatic envelope models useful? Global Ecology and Biogeography, 12, 361-371.

Potter, S., Cooper, S.J.B., Metcalfe, C.J., Taggart, D.A. \& Eldridge, M.D.B. (2012) Phylogenetic relationships within Petrogale (Marsupialia: Macropodidae) and their 
biogeographic history within Australia. Molecular Phylogenetics and Evolution, 62, 640652.

R Development Core Team (2010) R: a language and environment for statistical computing. R Foundation for Statistical Computing, Vienna, Austria.

Randin, C.F., Engler, R., Normand, S., Zappa, M., Zimmermann, N.E., Pearman, P.B., Vittoz, P., Thuiller, W.\& Guisan, A. (2009) Climate change and plant distribution: local models predict high-elevation persistence. Global Change Biology, 15, 1557-1569.

Short, J. (1982) Habitat requirements of the brush-tailed rock-wallaby, Petrogale penicillata, in New South Wales. Australian Wildlife Research, 9, 239-246.

Soberón, J. (2007) Grinnellian and Eltonian niches and geographic distributions of species. Ecology Letters, 10, 1115-1123.

Soria-Auza, R.W., Kessler, M., Bach, K., Barajas-Barbosa, P.M., Lehnert, M., Herzog, S.K. \& Böhner, J. (2010) Impact of the quality of climate models for modelling species occurrences in countries with poor climatic documentation: a case study from Bolivia. Ecological Modelling, 221, 1221-1229.

Storlie, C.J., Phillips, B.L., VanDerWal, J.J. \& Williams, S.E. (2013) Improved spatial estimates of climate predict patchier species distributions. Diversity and Distributions, 19, $1106-1113$.

Suggitt, A.J., Gillingham, P.K., Hill, J.K., Huntley, B., Kunin, W.E., Roy, D.B. \& Thomas, C.D. (2011) Habitat microclimates drive fine-scale variation in extreme temperatures. Oikos, $120,1-8$. 
Swets, J.A. (1988) Measuring the accuracy of diagnostic systems. Science, 240, 1285-1293.

Thompson, R.M., Beardall, J., Beringer, J., Grace, M. \& Sardina, P. (2013) Means and extremes: building variability into community-level climate change experiments. Ecology Letters, 16, 799-806.

Trivedi, M.R., Berry, P.M., Morecroft, M.D. \& Dawson, T.P. (2008) Spatial scale affects bioclimate model projections of climate change impacts on mountain plants. Global Change Biology, 14, 1089-1103.

Wong, V. (1993) The brush-tailed rock-wallaby (Petrogale penicillata) in southern New South Wales - distribution and abundance management recommendations. Unpublished report to NSW National Parks and Wildlife Service, Hurstville, NSW.

Wong, V. (1997) The Shoalhaven brush-tailed rock-wallabies; surveys and monitoring, January-March 1997. Unpublished report to the NSW National Parks and Wildlife Service, Hurstville, NSW.

\section{BIOSKETCH}

The research team is multidisciplinary, with research interests spanning topoclimate, macropod ecology and species distribution modelling. The members of the team have a shared interest in understanding the threatening processes and conservation needs of species at a regional scale. 
Author contributions: all authors conceived the ideas and contributed to the writing; M.B.A. and J.R.G. collected topoclimatic data; M.C. collated wallaby data; M.B.A. analysed the data and led the writing.

Editor: W. Daniel Kissling 
1 Table 1 The correlations ( $r$ ) between the continuous variables used as predictors. These correlations were based on a combined dataset, and 2 varied for the 10 randomized subsets used to produce the models. Minimum temperature of the coldest period (MinTmp), maximum temperature 3 of the warmest period (MaxTmp), mean annual temperature (AnnTmp) and mean annual precipitation (AnnPr) were macroclimatic predictors; the 4 5th and 95th percentiles of minimum temperatures (MinT95 and MinT5), 95th percentile of maximum temperatures (MaxT95) and 5th percentile 5 of humidity (MinH5) were topoclimatic predictors; elevation (Elev), slope (Slp), cosine of aspect (Asp) and relative elevation (RelElev) were 6 topographical predictors; and canopy cover (FolCov) and the amount of cleared area within $1600 \mathrm{~m}$ (ClrCont) were continuous habitat predictors 7 (see text for full details). Vegetation community (VegCom) was an additional categorical habitat predictor and is not shown. Macroclimatic 8 variables were at c. 50-m resolution, VegCom was at 200-m resolution, and the remaining predictors were at 25-m resolution.

AnnPr MinTmp MaxTmp AnnTmp MaxT95 MinH5 MinT95 MinT5 FolCov RelElev Elev ClrCont Slp

$\begin{array}{lccccccc}\text { MinTmp } & 0.48 & & & & & \\ \text { MaxTmp } & -0.72 & -0.01 & & & & \\ \text { AnnTmp } & 0.04 & 0.82 & 0.53 & & & \\ \text { MaxT95 } & -0.83 & -0.20 & 0.81 & 0.22 & & & \\ \text { MinH5 } & 0.87 & 0.43 & -0.72 & 0.03 & -0.92 & & \\ \text { MinT95 } & 0.15 & 0.82 & 0.41 & 0.94 & 0.10 & 0.10 & \\ \text { MinT5 } & 0.64 & 0.56 & -0.49 & 0.22 & -0.64 & 0.65 & 0.45\end{array}$




\begin{tabular}{lccccccccccccc} 
FolCov & 0.45 & 0.17 & -0.49 & -0.12 & -0.61 & 0.55 & 0.09 & 0.71 & & & & \\
RelElev & 0.29 & -0.07 & -0.46 & -0.32 & -0.43 & 0.32 & -0.06 & 0.65 & 0.49 & & & \\
Elev & -0.10 & -0.87 & -0.42 & -0.96 & -0.20 & -0.05 & -0.93 & -0.29 & 0.05 & 0.30 & & \\
ClrCont & -0.44 & -0.19 & 0.50 & 0.10 & 0.57 & -0.49 & -0.09 & -0.72 & -0.79 & -0.52 & -0.03 & \\
Slp & 0.22 & 0.04 & -0.32 & -0.14 & -0.36 & 0.31 & 0.02 & 0.59 & 0.48 & 0.61 & 0.12 & -0.54 & \\
Asp & -0.05 & 0.01 & 0.06 & 0.03 & 0.21 & -0.16 & 0.04 & -0.11 & -0.18 & -0.08 & -0.03 & 0.08 & -0.09 \\
\hline
\end{tabular}


9 Figure 1 The elevation (m) and projected foliage cover of vegetation (\%) in the Hunter

10 Valley region of New South Wales, Australia (31.2-33.4 $\left.{ }^{\circ} \mathrm{S}, 148.6-153.0^{\circ} \mathrm{E}\right)$. The recorded

11 locations of brush-tailed rock-wallabies (Petrogale penicillata) are illustrated with white dots

12 in the top panel and black dots in the bottom panel.

13 Figure 2 The relative performances of different models for the distribution of brush-

14 tailed rock-wallaby (Petrogale penicillata) colonies, where each dot represents the average

15 performance of a model with a different set of predictors. Performance was assessed using the Akaike information criterion (AIC) of 10 randomly selected training datasets and the area under the receiver operating characteristic curve (AUC) for the corresponding test datasets. Error bars illustrate the standard deviation of the 10 datasets, and models that consistently performed better than the others over the 10 datasets are labelled individually (RelElev, relative elevation; MinT5, 5th percentile of minimum temperatures; ClrCont, amount of cleared land within 1600 m; AnnPr, mean annual precipitation; Slp, slope; VegCom, vegetation community). Models were assessed using (a) one, (b) two and (c) three predictors.

23 Figure 3 The response curves produced by univariate (left) and multivariate (right) generalized additive models for brush-tailed rock wallaby (Petrogale penicillata) colonies in the Hunter Valley, New South Wales, Australia. Ten lines are shown for the 10 replicate datasets created with different randomizations of the data. The right panels show the curves from the best three-predictor model, where the response curves for each factor were produced by holding the values of the other factors at their optimal value [i.e. the 5th percentile of minimum temperatures $($ MinT5 $)=9.1$, mean annual precipitation $(A n n P r)=552$ or amount 30 of cleared land within $1600 \mathrm{~m}($ ClrCont $)=0]$. 
31 Figure 4 The predicted habitat suitability maps for brush-tailed rock-wallabies

32 (Petrogale penicillata) produced using (a) a one-predictor model based on the 5th percentile

33 of minimum temperatures (MinT5), (b) a two-predictor model based on MinT5 and mean

34 annual precipitation (AnnPr), and (c) a three-predictor model based on MinT5, AnnPr and the

35 amount of cleared land within $1600 \mathrm{~m}$ (ClrCont). Large dots show the locations of known

36 extant colonies, while smaller dots are associated with extinct, unknown or non-colony

37 records.

38 


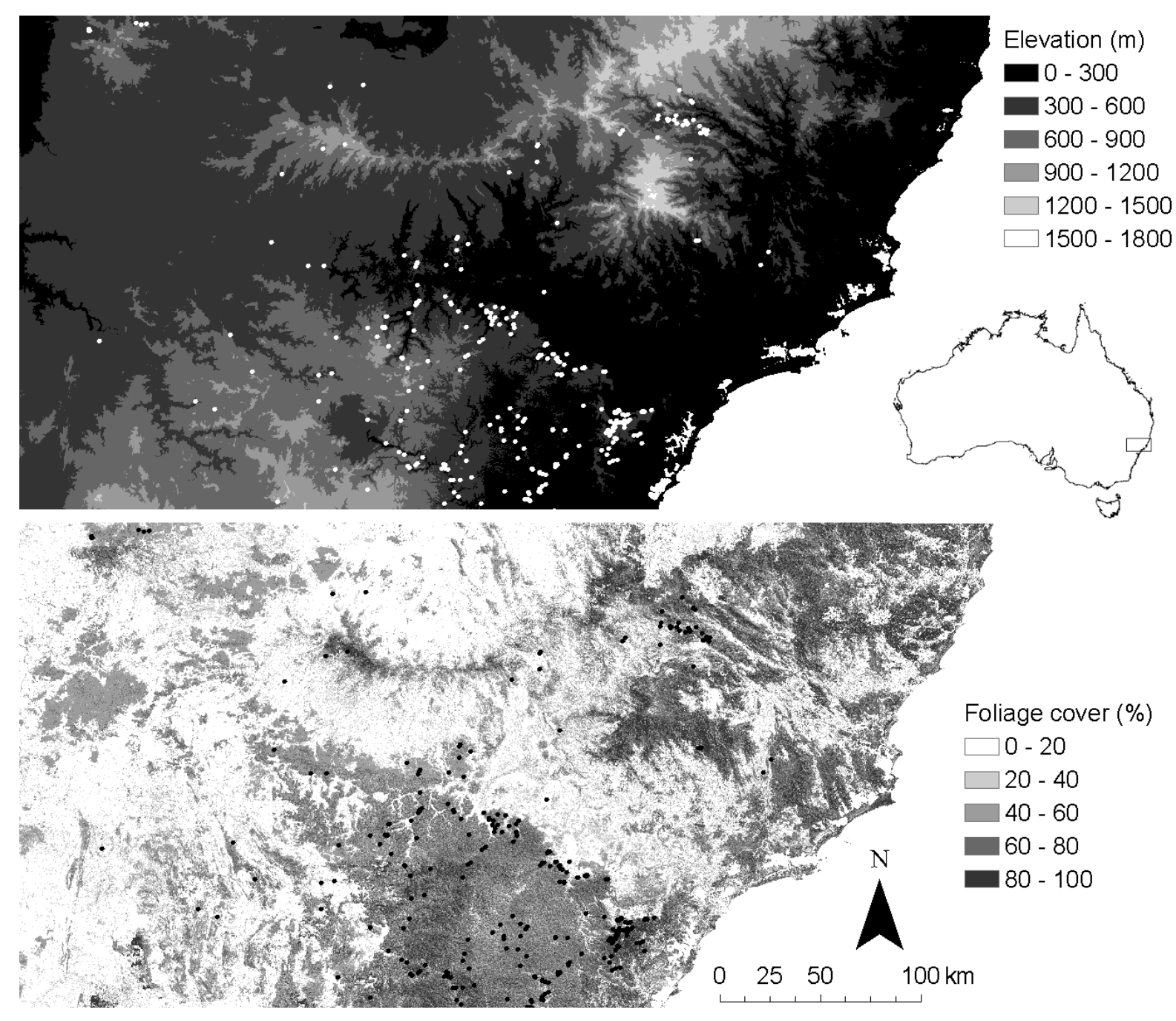

Fig. 1 

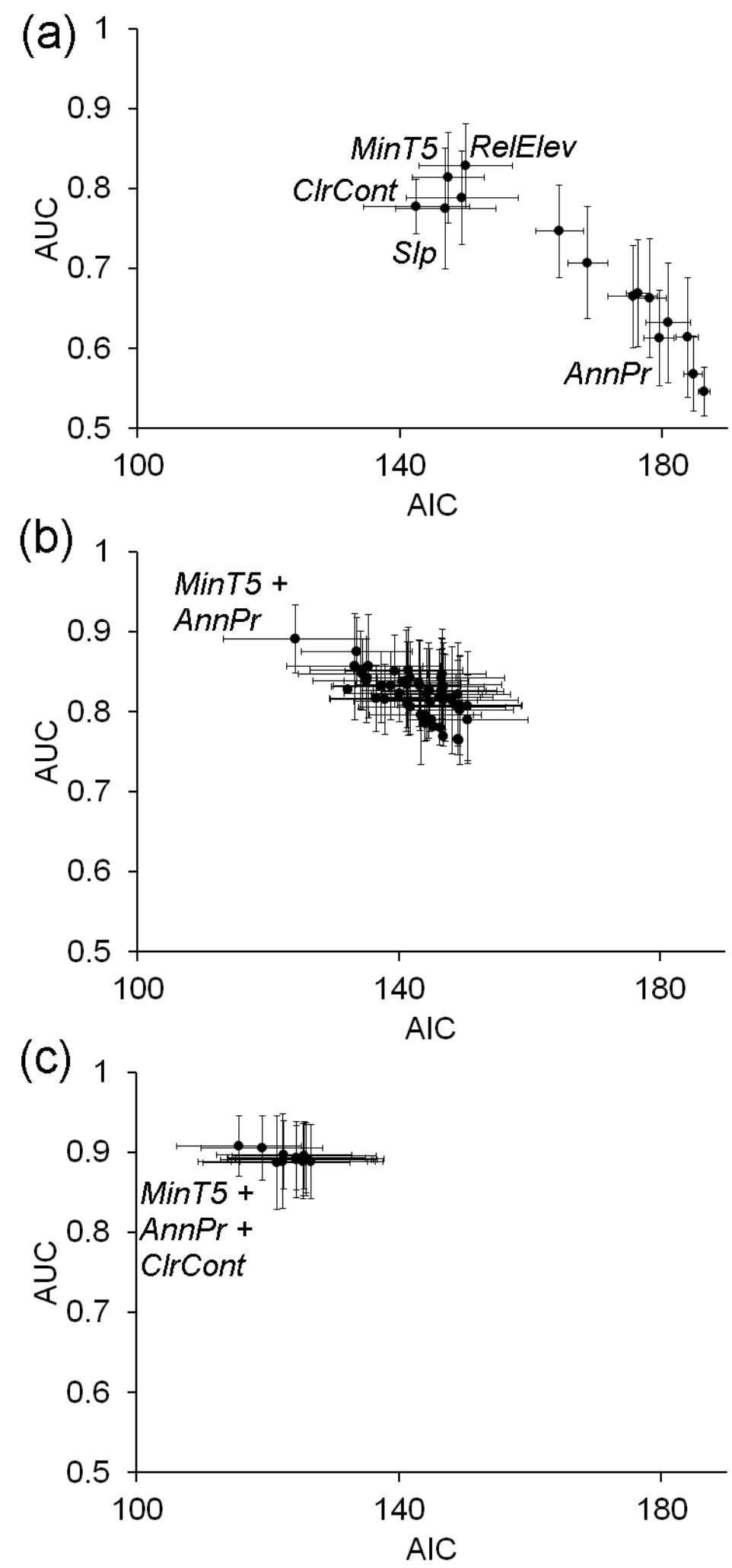

$43 \quad$ Fig. 2 

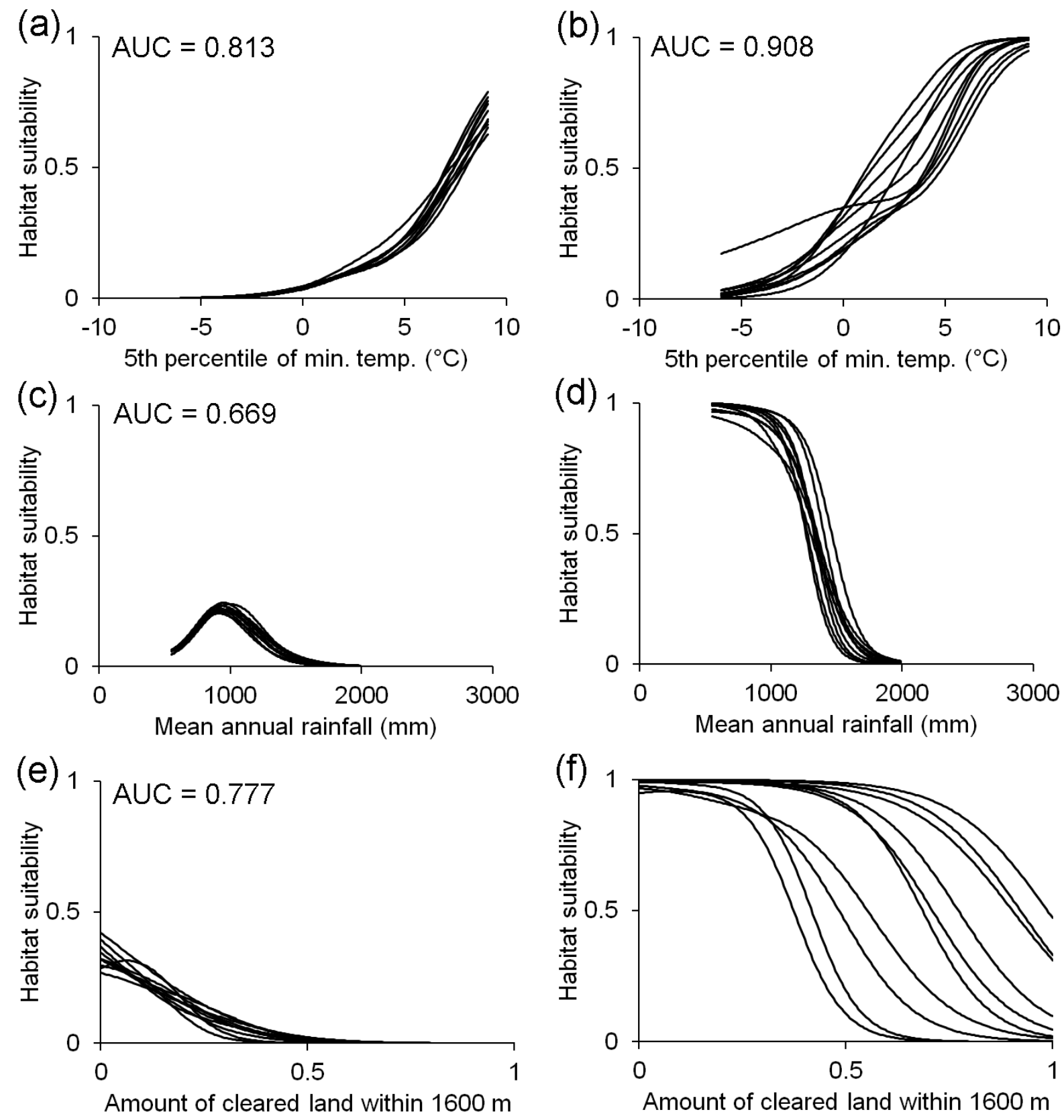

$45 \quad$ Fig. 3 
(a) MinT5
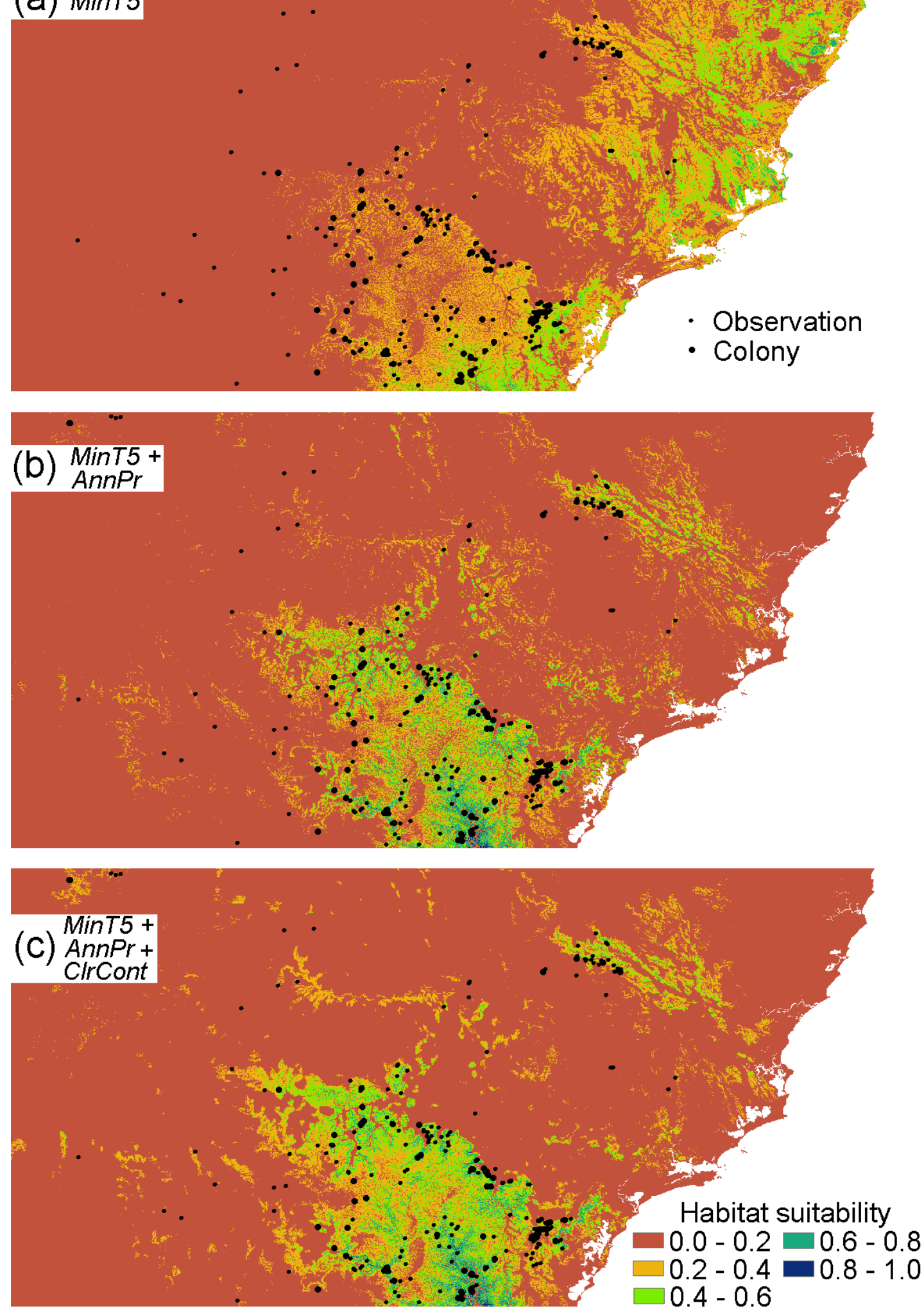